\title{
Prevalence and Correlates of Problematic Internet Experiences and Computer-Using Time: A Two-Year Longitudinal Study in Korean School Children
}

\author{
Su-Jin Yang ${ }^{\circledR}$, Robert Stewart², Ju-Yeon Lee ${ }^{3}$, Jae-Min Kim ${ }^{3}$, \\ Sung-Wan $\mathrm{Kim}^{3}$, II-Seon Shin ${ }^{3}$, and Jin-Sang Yoon ${ }^{3}$ \\ ${ }^{1}$ Department of Psychiatry, Gangnam Severance Hospital, Seoul, Republic of Korea \\ 2Institute of Psychiatry, Section of Epidemiology, King's College London, London, UK \\ ${ }^{3}$ Department of Psychiatry, Chonnam National University Medical School, Gwangju, Republic of Korea
}

Objective To measure the prevalence of and factors associated with online inappropriate sexual exposure, cyber-bullying victimisation, and computer-using time in early adolescence.

Methods A two-year, prospective school survey was performed with 1,173 children aged 13 at baseline. Data collected included demographic factors, bullying experience, depression, anxiety, coping strategies, self-esteem, psychopathology, attention-deficit hyperactivity disorder symptoms, and school performance. These factors were investigated in relation to problematic Internet experiences and computer-using time at age 15 .

Results The prevalence of online inappropriate sexual exposure, cyber-bullying victimisation, academic-purpose computer overuse, and game-purpose computer overuse was $31.6 \%, 19.2 \%, 8.5 \%$, and $21.8 \%$, respectively, at age 15 . Having older siblings, more weekly pocket money, depressive symptoms, anxiety symptoms, and passive coping strategy were associated with reported online sexual harassment. Male gender, depressive symptoms, and anxiety symptoms were associated with reported cyber-bullying victimisation. Female gender was associated with academic-purpose computer overuse, while male gender, lower academic level, increased height, and having older siblings were associated with game-purpose computer-overuse.

Conclusion Different environmental and psychological factors predicted different aspects of problematic Internet experiences and computer-using time. This knowledge is important for framing public health interventions to educate adolescents about, and prevent, internet-derived problems.

Psychiatry Investig 2014;11:24-31

Key Words Online sexual exposure, Cyber-bullying, Computer overuse, Longitudinal study, Adolescent.

\section{INTRODUCTION}

Concern over the impact of Internet use on adolescents has developed over the last 20 years. ${ }^{1,2}$ The issue can be confusing due to diverging perspectives of the Internet either as a new tool for education and recreation, or as a potential threat to physical and/or psychological well-being. ${ }^{3}$ Public health officials, educators, law enforcement officers, and parents share

Received: March 5, 2013 Revised: June 3, 2013

Accepted: June 5, 2013 Available online: January 21, 2014

$\triangle$ Correspondence: Su-Jin Yang, MD, PhD

Department of Psychiatry, Gangnam Severance Hospital, 211 Eonju-ro, Gangnam-gu, Seoul 135-720, Republic of Korea

Tel: +82-2-2019-3345, Fax: +82-2-3462-4304, E-mail: sjyang@yuhs.ac

@ This is an Open Access article distributed under the terms of the Creative Commons Attribution Non-Commercial License (http://creativecommons.org/licenses/bync/3.0) which permits unrestricted non-commercial use, distribution, and reproduction in any medium, provided the original work is properly cited. concerns over problematic Internet experiences and computer overuse. They give the most attention to the sexual exploitation of youth and cyber-bullying victimisation..$^{4-8}$ There are also multiple views on the potential vulnerability of adolescents: one of inexperience (e.g., adolescents with developmental disabilities vulnerable to online fraud) and another of over-experience (technologically knowledgeable adolescents with risk-taking tendencies). These potentially complex risk profiles present a challenge for prevention and protection.

Through the rapid spread of Internet use, new psychological terminology has been coined, such as "Internet addiction", 2,9 and "pathological Internet use,", with no universally accepted definitions. Generally, these terms represent the reduced ability of individuals to control their Internet use, resulting in significant distress and/or functional impairment in daily life. ${ }^{2,11}$ Although a strict quantification of daily computer 
use is not sufficient to define these phenomena, it is common in clinical experience to see computer overuse related to adolescents' preoccupation with the Internet, functional impairment, and conflicts at home and at school. Further in-depth investigation of computer overuse is required for the development of strategies to prevent or reduce functional impairment, and to distinguish the pathological entity of "Internet addiction" from problematic computer overuse. However, there is little empirical evidence on risk factors for various problematic Internet experiences and computer overuse in young people. In addition, previous studies have not gathered sufficient information to differentiate between online inappropriate sexual exposure, cyber-bullying victimisation, and computer overuse. To address these deficiencies based on available evidence, we analysed data from a two-year longitudinal study of a large sample of Korean middle-school children.

\section{METHODS}

\section{Procedure and participants}

The baseline survey in 2004 included 1,173 seventh grade students (age 13-14 years) from three middle schools in Kwangju, South Korea, and their parents. In their classrooms during school hours, and under the direction of the project psychiatrist, each participant provided data and completed all questionnaires, which were appropriately validated for seventh graders. This took an average of 45 minutes. Each parent received a sealed questionnaire and information via the participating young person, completed the questionnaire at home, and returned it in a sealed envelope. Two years later, when the adolescents were in the ninth grade (age 15-16 years), a follow-up school visit was conducted with attempts made to include all previous participants, as well as other current students in that grade. Of 1,173 adolescents who were eligible at baseline, 936 participated in the initial survey, $835(89.2 \%)$ of whom also participated at follow-up. The number of adolescents who had complete data at baseline and follow-up was 566 (67.8\%). The remainder had at least one variable missing. Essentially identical procedures were used to identify all psychopathology, although online inappropriate sexual exposure, cyber-bullying victimisation, and computer overuse were only evaluated at follow-up. All participants and parents gave written informed consent at each examination. This study was approved by the Chonnam National University Hospital Institutional Review Board.

\section{Assessments and measurements}

\section{Online inappropriate sexual exposure}

We used two questions: 1) "In the past year, did anyone ever use the Internet to give you sexual information (e.g., a description, picture, or video) that was unwanted or wanted?", 2) "In the past year, have you ever engaged in online sexual activities or sexual talks that were unwanted or wanted?"

\section{Cyber-bullying victimisation}

We used four self-report items completed by children about threatening emails/texts, malicious rumours or abuse of personal information involving the use of the Internet and/or mobile phones, to evaluate victimisation from cyber-bullying. Internal consistency for items was found to be satisfactory (Cronbach's alpha 0.67$)$. Until now, no established questionnaire cut-offs existed for characterising cyber-bullying victimisation, ${ }^{12}$ and it is defined here on the basis of a score at or above the upper quartile.

\section{Computer-using time}

The questionnaire comprised items to determine the duration of computer use per day (estimated separately according to whether it was for the purposes of academic work or for game-playing). In terms of defining 'overuse', there is no current standard. Previous research had found that internet-addicted Korean adolescents spent a mean (SD) 3.64 (2.19) hours per day online compared to 2.44 (1.55) in non-addicted adolescents. ${ }^{13}$ Therefore, for this study, over 3 hours computer use per day was defined a priori as computer-overuse.

\section{Bullying}

We used two self-report scales completed by the young participants to ascertain 'traditional' (i.e., non-cyber) bullying: the Peer-Victimisation Scale (PVS) and the Bullying Behaviour Scale (BBS) ${ }^{14}$ The PVS consists of six compulsory items, three of which refer to being a victim of negative physical actions and three of which refer to being a victim of negative verbal actions. The BBS is based on the PVS; it involves changing the phrasing from passive to active. For the purpose of classification, researchers used a cut-off score of 2.50 or above on both the PVS and the BBS. Korean versions of the PVS and the BBS have been validated. ${ }^{15}$ Cut-off scores of 2.60 or above on the PVS and 2.50 or above on BBS were used to categorise victimisation and perpetration, respectively.

\section{Depression}

We administered the Children's Depression Inventory (CDI). ${ }^{16}$ The CDI requires a third-grade reading level and is suitable for children between the ages of seven and 17. Total scores range from 0 to 54, with higher scores indicating higher levels of depression. Kovacs recommended that scores $\geq 17$ in a heterogeneous population be considered indicative of depression and the reliability and validity of the Korean form of 
the CDI have been established as acceptable. ${ }^{17}$

\section{Anxiety}

We used the State-Trait Anxiety Inventory for Children (STAI-C) ${ }_{1}^{18}$ which includes 20 'State Anxiety' and 20 'Trait Anxiety' items. Responses are scored on a scale of 1 to 3, and total scores range from 20 to 60 , with higher scores reflecting greater anxiety. The reliability and validity of the Korean form of the STAI-C have been established. ${ }^{19}$ In this study, we defined relative anxiety on the basis of scores at or above the median.

\section{Self-esteem}

We used the short version of the Self-Esteem Inventory (SEI). ${ }^{20}$ The Korean translation includes 25 trait-descriptive sentences, to which subjects respond by indicating whether the sentences describe them. ${ }^{21}$ Total SEI scores range from 0 to 25, with higher scores reflecting higher self-esteem. Scores at or below the median were used to define relative low selfesteem.

\section{Coping strategies}

We used the adolescent version of the Ways of Stress Coping Checklist. ${ }^{22}$ An appropriately modified Korean version has been developed with factor structures of 'problem-solving strategies' and 'passive strategies. ${ }^{23}$ Scores at or above the median defined good problem-solving strategies and passive strategies, respectively.

\section{Psychopathology}

The Strengths and Difficulties Questionnaire (SDQ-S) was administered, which includes 25 items, divided into five scales of five items each: hyperactivity, emotional symptoms, conduct problems, peer problems, and prosocial behaviour. ${ }^{24} \mathrm{~A}$ score of total difficulties is computed by combining all scales except the prosocial behaviour scale. For each scale except for the prosocial behaviour scale, higher scores indicate more problems. The sum of the scores ranges from 0 to 40 . The Korean translation has been evaluated and reported as satisfactory, and we used the same cut-off ( $\geq 20$ for total psychopathology) applied in previous Korean research. ${ }^{25}$

\section{Attention deficit hyperactivity symptoms}

Parents completed the Korean version of DuPaul's Attention Deficit Hyperactivity Disorder Rating Scale (K-ARS). ${ }^{26}$ $\mathrm{K}$-ARS has an 18-item measure used to assess inattention and hyperactivity. Items are rated on a four-point scale $(0=$ never or rarely, $3=$ =ery often). The K-ARS has good reliability and validity among Korean children, with scores $\geq 17$ recommended for defining ADHD. ${ }^{26}$

\section{Height and weight}

Routine data were made available from each school on students' height and weight. School health nurses measure height and weight annually, with the student wearing underwear and not wearing shoes. We divided the adolescents into three groups: $<10$ th percentile, $10-90$ th percentile, and $\geq 90$ th percentile, according to their height and weight.

\section{Socio-demographic characteristics}

Data were recorded on gender, family structure, number of friends, birth order, weekly pocket money, five levels of socioeconomic status, and five levels of academic achievement. We categorised family structure according to whether the participant was living with one or both parents. 'Number of friends' was grouped into " 0 ", " $1-2$ ", " $3-4$ ", " $5-9$ ", and " $10+$ ". Birth order was divided into whether or not the participant had siblings. Weekly pocket money was categorised by USD equivalence into five groups $\left(<5,5-9,10^{-14}, 15-19\right.$, and $\left.20+\right)$.

\section{Statistical analysis}

Statistical analyses were conducted using Stata 11 (StataCorp, College Station, TX, USA). Unadjusted logistic regression analyses were carried out to examine associations between environmental and psychological variables at baseline with respect to online inappropriate sexual exposure, cyberbullying victimisation, and computer-using time at followup. Multivariable logistic regression models were then used to test the independence of these associations. These models were assembled as follows: first, environmental factors (sociodemographic and anthropometric measures) were entered simultaneously to investigate their mutual independence; next, the two variables measuring perpetration of, and victimisation by, traditional bullying at baseline were entered, adjusted for each other and the previously entered variables; next, the psychological variables were entered separately, adjusted for previous traditional bullying and environmental factors, but not adjusted for each other, because of the risk of colinearity.

\section{Imputation of missing data}

We imputed data on children who participated at follow-up and had missing data points. We describe the extent and distribution of missing data in Table 1. To minimise the impact of missing data, we used multiple imputations (MI) by chained equation, combined using Rubin's rules in Stata to impute missing data. ${ }^{27}$ Thirty copies of the data were formed in the imputation process, each with missing data imputed. The MI data augmentation procedure used here assumes that the data have a multivariate normal distribution. Suitable transformations were necessary for this assumption to hold. After im- 
Table 1. Descriptive statistics and data completeness for the study sample

\begin{tabular}{lccccl}
\hline \multicolumn{1}{c}{ Characteristics at age 13 } & Informant & Mean (SD) or (\%) & Range & Number (\%) & Instruments or examples of items \\
\hline Low academic level & Parent & 7.7 & - & $835(100)$ & Five-level achievement \\
Height, cm & Teacher & $155.5(6.80)$ & $127-175$ & $833(99.8)$ & By school nurse \\
Weight, kg & Teacher & $46.8(8.90)$ & $24-84$ & $830(99.4)$ & By school nurse \\
Number of friends & Self & $3.7(3.16)$ & $0-30$ & $835(100)$ & Grouped into 0, 1-2, 3-4, 5-9, and over 10 \\
Weekly pocket money & Self & $17.9(4.17)$ & $0-90$ & $835(100)$ & $<5,5-9,10-14,15-19$, and over 20 USD \\
Low economic status & Parent & 12.1 & - & $830(99.4)$ & Five-level economic status \\
First born child & Parent & 49.5 & - & $580(69.5)$ & \\
Single parent & Parent & 9.5 & - & $831(99.5)$ & \\
Perpetration of bullying & Self & $11.9(3.20)$ & $6-24$ & $834(99.9)$ & Bullying Behaviour Scale \\
Victimization of bullying & Self & $11.1(3.20)$ & $6-24$ & $834(99.9)$ & Peer-Victimization Scale \\
Depression & Self & $14.6(6.29)$ & $0-46$ & $834(99.9)$ & Children's Depression Inventory \\
Anxiety & Self & $66.0(12.26)$ & $39-114$ & $833(99.8)$ & State-Trait Anxiety Inventory for Children \\
Self esteem & Self & $13.5(4.80)$ & $1-25$ & $830(99.4)$ & Short version the Self-Esteem Inventory \\
Passive Coping strategy & Self & $24.0(6.53)$ & $12-48$ & $830(99.4)$ & Ways of Coping Checklist \\
Total psychopathology & Self & $13.5(4.80)$ & $1-32$ & $819(98.1)$ & Strengths and Difficulties Questionnaire \\
Attention-deficit hyperactivity & Parent & $8.3(7.11)$ & $0-40$ & $570(68.3)$ & Korean version of ADHD Rating Scale \\
disorder symptoms & & & & \\
\hline
\end{tabular}

putation, the complete data were transformed back to their original scale prior to any analyses being performed. All subsequent analyses were conducted using imputed data.

\section{RESULTS}

\section{Sample description and prevalence of problematic internet experience and computer-using time}

The adolescents at baseline comprised 443 boys (47.5\%) and 489 girls, and those at follow-up comprised 382 boys (45.8\%) and 453 girls. The prevalence of online inappropriate sexual exposure and cyber-bullying victimisation at followup were 264 (31.6\%) and 169 (19.2\%), respectively. The mean (SD) durations of academic- and game-related computer-use at follow-up were $1.35(0.88)$ and $2.03(1.30)$ hours per day, respectively. The prevalence of computer overuse ( $>3$ hours/ day) for academic purposes was $71(8.5 \%)$, and for gameplaying, it was $182(21.8 \%)$. There were no school differences in sample characteristics (data not shown).

\section{Baseline factors associated with online inappropriate sexual exposure, cyber-bullying victimisation, and computer-using time at follow-up}

As summarised in Table 2, unadjusted analyses indicated the following baseline factors were associated with online inappropriate sexual exposure at follow-up: higher than average height, heavier than average weight, more weekly pocket money, having older siblings, depression, and use of a passive coping strategy. Baseline factors associated with cyber-bully- ing victimisation at follow-up were: male gender, previous perpetration of traditional bullying, previous victimisation by traditional bullying, higher depression, higher anxiety, use of a passive coping strategy, and higher ADHD symptoms. Baseline factors associated with academic-purpose computer use at follow-up: female gender and lower academic level. The following factors were significantly associated with game-related computer use at follow-up: male gender, lower academic level, having older siblings, and previous victimisation by traditional bullying.

\section{Multi-variable regression models of problematic internet experiences}

After adjustment for other environmental factors (as summarised in columns 1 and 2 of Table 3), more weekly pocket money and having older siblings remained associated with online inappropriate sexual exposure, and male gender remained associated with cyber-bullying victimisation. After adjustment for previous bullying experience and environmental factors, higher depression and higher anxiety remained associated with online inappropriate sexual exposure and cyber-bullying victimisation, and passive coping strategies remained associated with online inappropriate sexual exposure.

\section{Multi-variable regression models of computer use}

After adjustment for other environmental factors (as summarised in columns 3 and 4 of Table 3), female gender remained associated with academic-purpose computer-using 
Table 2. Associations between characteristics at age 13 years with involvement in problematic internet experiences and computer-overuse by age 15 years*

\begin{tabular}{|c|c|c|c|c|c|c|c|c|}
\hline & \multicolumn{2}{|c|}{$\begin{array}{c}\text { Online inappropriate } \\
\text { sexual exposure }\end{array}$} & \multicolumn{2}{|c|}{$\begin{array}{l}\text { Cyber-bullying } \\
\text { victimization }\end{array}$} & \multicolumn{2}{|c|}{$\begin{array}{l}\text { Academic-purpose } \\
\text { computer-overuse }\end{array}$} & \multicolumn{2}{|c|}{$\begin{array}{c}\text { Game-purpose } \\
\text { computer-overuse }\end{array}$} \\
\hline & OR $(95 \% \mathrm{CI})$ & $\mathrm{p}$ value & OR $(95 \%$ CI $)$ & $\mathrm{p}$ value & OR $(95 \% \mathrm{CI})$ & $\mathrm{p}$ value & OR $(95 \% \mathrm{CI})$ & $\mathrm{p}$ value \\
\hline \multicolumn{9}{|l|}{ Environmental factors } \\
\hline Male & $0.99(0.77,1.29)$ & 0.984 & $1.76(1.35,2.28)$ & $<0.001$ & $0.67(0.52,0.87)$ & 0.003 & $1.92(1.43,2.57)$ & $<0.001$ \\
\hline Low academic level & $0.92(0.82,1.04)$ & 0.195 & $1.08(0.96,1.22)$ & 0.217 & $1.19(1.02,1.34)$ & 0.020 & $1.23(1.08,1.40)$ & 0.001 \\
\hline Height, $\geq 90$ percentile & $1.12(1.01,1.25)$ & 0.027 & $1.01(0.92,1.12)$ & 0.826 & $1.06(0.96,1.17)$ & 0.256 & $1.09(0.99,1.21)$ & 0.073 \\
\hline Weight, $\geq 90$ percentile & $1.10(1.01,1.20)$ & 0.027 & $1.07(0.98,1.16)$ & 0.116 & $1.06(0.98,1.14)$ & 0.147 & $1.02(0.94,1.11)$ & 0.647 \\
\hline Fewer friends, 5 groups & $0.98(0.86,1.12)$ & 0.790 & $1.01(0.89,1.14)$ & 0.889 & $0.98(0.86,1.11)$ & 0.741 & $1.03(0.89,1.19)$ & 0.674 \\
\hline $\begin{array}{l}\text { Higher weekly pocket } \\
\text { money, } 5 \text { groups }\end{array}$ & $1.09(1.01,1.17)$ & 0.025 & $1.03(0.96,1.11)$ & 0.343 & $0.95(0.89,1.02)$ & 0.138 & $1.04(0.96,1.12)$ & 0.338 \\
\hline $\begin{array}{l}\text { Lower economic status, } \\
5 \text { groups }\end{array}$ & $0.93(0.79,1.10)$ & 0.415 & $1.04(0.88,1.23)$ & 0.628 & $1.11(0.95,1.31)$ & 0.198 & $1.11(0.93,1.34)$ & 0.251 \\
\hline $\begin{array}{l}\text { Birth order, not first } \\
\text { one }\end{array}$ & $1.37(1.01,1.86)$ & 0.041 & $1.20(0.91,1.58)$ & 0.200 & $1.00(0.76,1.33)$ & 0.987 & $1.75(1.27,2.43)$ & 0.001 \\
\hline Single parent & $1.37(0.86,2.18)$ & 0.179 & $0.88(0.56,1.39)$ & 0.580 & $1.10(0.69,1.74)$ & 0.698 & $1.40(0.85,2.30)$ & 0.181 \\
\hline \multicolumn{9}{|l|}{ Bullying experience } \\
\hline Perpetration group & $1.01(0.71,1.43)$ & 0.965 & $1.52(1.11,2.08)$ & 0.009 & $0.97(0.69,1.35)$ & 0.838 & $1.09(0.77,1.55)$ & 0.624 \\
\hline Victimization group & $1.09(0.84,1.43)$ & 0.501 & $1.37(1.09,1.73)$ & 0.008 & $1.08(0.82,1.42)$ & 0.982 & $1.06(0.79,1.43)$ & 0.682 \\
\hline Psychological factors & & & & & $0.99(0.77,1.28)$ & 0.982 & $1.14(0.86,1.50)$ & 0.366 \\
\hline Depression & $1.36(1.03,1.78)$ & 0.028 & $1.61(1.22,2.01)$ & 0.001 & $0.99(0.77,1.29)$ & 0.987 & $1.06(0.79,1.44)$ & 0.685 \\
\hline Anxiety & $1.29(0.99,1.66)$ & 0.053 & $1.57(1.20,2.05)$ & 0.001 & $0.95(0.74,1.22)$ & 0.676 & $1.09(0.82,1.46)$ & 0.541 \\
\hline Lower Self esteem & $1.27(0.96,1.67)$ & 0.093 & $1.15(0.89,1.50)$ & 0.281 & $0.91(0.60,1.38)$ & 0.649 & $0.93(0.59,1.47)$ & 0.764 \\
\hline Passive coping strategy & $1.63(1.21,2.19)$ & 0.001 & $1.34(1.01,1.77)$ & 0.040 & $0.95(0.63,1.43)$ & 0.802 & $0.96(0.59,1.55)$ & 0.859 \\
\hline Total psychopathology & $0.93(0.61,1.44)$ & 0.755 & $1.34(0.88,2.04)$ & 0.172 & $1.08(0.82,1.42)$ & 0.982 & $1.06(0.79,1.43)$ & 0.682 \\
\hline ADHD symptoms & $1.25(0.82,1.90)$ & 0.299 & $1.61(1.03,2.51)$ & 0.038 & $0.99(0.77,1.28)$ & 0.982 & $1.14(0.86,1.50)$ & 0.366 \\
\hline
\end{tabular}

*analysis with imputed data. ADHD: attention-deficit hyperactivity disorder, CI: confidence interval, OR: odds ratio

time, and male gender, lower academic achievement, higher than average height, and having older siblings remained associated with game-related computer-using time.

\section{DISCUSSION}

In a prospective longitudinal study of middle school students in South Korea, we investigated the prevalence of and factors predicting later involvement in problematic Internet experience and computer overuse.

The prevalence of online inappropriate sexual exposure was $31.6 \%$. One 2001 telephone survey reported that $19 \%$ of young people who used the Internet regularly were targets of unwanted sexual solicitation within a year. ${ }^{4}$ In $2007,43 \%$ of young clients who received treatment for Internet-related problems reported the intentional use of pornography. ${ }^{5}$ Our observed prevalence fell between these results. One possible explanation is that online inappropriate sexual exposure represents a relatively new and growing phenomenon affected by time trends as well as by assessment methods and settings. The rapidly increasing availability of Internet sites presents increasing opportunities for online inappropriate sexual exposure. The prevalence of cyber-bullying victimisation in the present study was $19.2 \%$, compared to previous reports of $6.6 \%$ to $15.6 \%$, depending on the assessment method/criteria, age groups, and time trends. ${ }^{6,728,29}$ Our relatively high prevalence may reflect the high levels and duration of Internet usage in Korea, with more than $95 \%$ of people under the age of 20 having used the Internet for over two years. ${ }^{30}$

The prevalence of computer overuse as defined in this study ( $>3$ hours/day) was $8.5 \%$ for academic purposes and $21.8 \%$ for game playing. As discussed earlier, a drawback with prevalence studies in this field has been the application of relatively vague terminology to describe levels of Internet use, such as 'borderline,' 'excessive,' 'at risk', and 'addictive, which have not been operationally defined or clinically validated. ${ }^{31}$ International prevalence rates for Internet addiction have ranged from $1.5 \%$ to $8.2 \%,{ }^{32}$ and previous studies have found the 
Table 3. Multi-variable logistic regression of associations between characteristics at age 13 with involvement in problematic internet experiences and computer-overuse by age 15 years

\begin{tabular}{|c|c|c|c|c|}
\hline \multirow{3}{*}{ Characteristics at age 13} & \multicolumn{4}{|c|}{$\begin{array}{l}\text { Associations with problematic internet experiences and } \\
\text { computer-overuse at age } 15 \text { years (odds ratio, } 95 \% \mathrm{CI} \text { ) }\end{array}$} \\
\hline & \multicolumn{2}{|c|}{ Problematic internet experiences } & \multicolumn{2}{|c|}{ Computer-overuse } \\
\hline & Sexual exposure & Victimization & Academic & Game \\
\hline \multicolumn{5}{|l|}{ Environmental factors ${ }^{\dagger}$} \\
\hline Male gender & $0.9(0.7,1.2)$ & $1.7(1.3,2.3)^{* *}$ & $0.6(0.5,0.8)^{* *}$ & $1.8(1.3,2.5)^{* *}$ \\
\hline Low academic level & $0.9(0.8,1.0)$ & $1.0(0.9,1.2)$ & $1.2(1.1,1.4)$ & $1.2(1.1,1.4)^{*}$ \\
\hline Height, $\geq 90$ percentile & $1.1(0.9,1.2)$ & $0.9(0.8,1.1)$ & $1.1(0.9,1.2)$ & $1.2(1.0,1.3)^{*}$ \\
\hline Weight, $\geq 90$ percentile & $1.1(1.0,1.2)$ & $1.0(1.0,1.2)$ & $1.1(1.0,1.2)$ & $0.9(0.8,1.0)$ \\
\hline Higher weekly pocket money, 5 groups & $1.1(1.0,1.2)^{*}$ & $1.0(0.9,1.1)$ & $1.0(0.9,1.0)$ & $1.0(0.9,1.1)$ \\
\hline Birth order, not first one & $1.4(1.0,1.9)^{*}$ & $1.2(0.9,1.5)$ & $1.0(0.7,1.3)$ & $1.7(1.2,2.3)^{*}$ \\
\hline \multicolumn{5}{|l|}{ Bullying behaviour/experience at age $13^{\ddagger}$} \\
\hline Perpetration group & $0.9(0.6,1.3)$ & $1.3(0.9,1.8)$ & $1.0(0.7,1.4)$ & $1.8(0.6,1.3)$ \\
\hline Victimization group & $1.1(0.8,1.5)$ & $1.2(0.9,1.5)$ & $1.0(0.8,1.4)$ & $1.3(0.9,1.7)$ \\
\hline \multicolumn{5}{|l|}{ Psychological factors at age $13^{\S}$} \\
\hline Depression & $1.5(1.1,2.0)^{*}$ & $1.6(1.1,2.1)^{*}$ & $1.0(0.7,1.3)$ & $1.0(0.7,1.3)$ \\
\hline Anxiety & $1.3(1.0,1.8)^{*}$ & $1.5(1.1,1.9)^{*}$ & $1.1(0.8,1.4)$ & $1.0(0.7,1.5)$ \\
\hline Passive coping strategy & $1.6(1.2,2.2)^{* *}$ & $1.3(1.0,1.7)$ & $1.0(0.8,1.4)$ & $1.0(0.7,1.4)$ \\
\hline ADHD symptoms & $1.4(0.9,2.1)$ & $1.3(0.8,2.1)$ & $1.0(0.6,1.5)$ & $0.8(0.4,1.4)$ \\
\hline
\end{tabular}

${ }^{*} \mathrm{p} \leq 0.05,{ }^{* *} \mathrm{p} \leq 0.001,{ }^{\dagger}$ mutually adjusted for other environmental factors but not for any other covariates, ${ }^{\star}$ mutually adjusted and adjusted for all environmental factors but not for psychological factors, \$individually entered and adjusted for both bullying measures and all environmental factors. ADHD: attention-deficit hyperactivity disorder, CI: confidence interval

prevalence of pathological gaming to be $7.6-9.9 \%{ }^{33}$ There are justifiable general concerns regarding the use of self-reported information, because of the risk of dishonest responses about adverse consequences, and misinterpretation of questionnaire items. For this reason, in our study we only used the reported time of computer use to evaluate overuse. This does not allow direct comparison with prevalence studies of Internet addiction; however, the high prevalence of game-related computer-using time does suggest the need for prevention programs.

The association between online inappropriate sexual exposure and higher weekly pocket money may reflect greater opportunities for using commercial gaming centres or Internet cafes. Many commercial broadband gaming centres in Korea, whose connection speed allows a higher level of activities, lack the closer monitoring of adolescent Internet use that may occur in the home. One study found that, in adolescents who had experienced online sexual harassment, being solicited while accessing the Internet away from home was associated with stronger feelings of vulnerability or potential embarrassment, due to others being aware of this experience. The study also found that these stronger feelings could be due to guilt, because these may be young people whose families object to them going online. ${ }^{4}$ Adolescents with an older sibling were also more likely to report online inappropriate sexual exposure, possible explanations being earlier exposure and an older sibling's influence on computer use habits.

Higher depression, higher anxiety, and passive coping strategies were also associated with online inappropriate sexual exposure. Some people use the Internet to avoid emotional difficulties in their lives, as illustrated by previous findings that both men and women with cybersex problems were more likely to exhibit maladaptive coping, conditioned behaviour, intimacy dysfunction, and addictive behaviour. ${ }^{34}$ Some have suggested that adolescents use the Internet as a coping mechanism against underlying psychological development issues, and the Identity and Intimacy issues from Eriksonian crises were found to be related to Internet dependence. ${ }^{35}$ As far as we are aware, there has been little longitudinal research into risk factors for online inappropriate sexual exposure. One cross-sectional study in adults found that subjective arousal and psychological symptoms such as depression, interpersonal sensitivity, and paranoid thinking were correlated with cybersex. ${ }^{36}$ Adolescents have to handle physical and psychological development issues such as sexual arousal and problems in academic work or relationships. These may increase the risk of online inappropriate sexual exposure if vulnerable people use the Internet to achieve positive emotional episodes 
and reduce depression and anxiety. One study reported that $25 \%$ of solicited young people reported high levels of distress after such incidents. ${ }^{4}$ Our study suggests that the vulnerable adolescents who passively cope with stress might benefit from educational interventions on how to avoid and/or cope with online inappropriate sexual exposure and that encourage help-seeking behaviour in the same way that is used to deal with bullying. ${ }^{37}$

Our study found that male gender was associated with cyber-bullying victimisation. However, in other research into cyber-bullying, gender differences have been inconsistent. ${ }^{28,29,38}$ Cyber-bullying is, in some respects, a form of indirect bullying (not face to face), which might be expected to appeal more to girls. However, the technological aspect of cyber-bullying might appeal more to boys. In this regard, our results suggest a need for further research in order to provide information for prevention and intervention programs. The association with depression at baseline is consistent with previous crosssectional evidence, ${ }^{7,28}$ but has received little longitudinal investigation to date. Higher anxiety was associated with cyberbullying victimisation, which, like depression, may reflect social avoidance, resulting in increased Internet exposure and likelihood of bullying through this medium.

Female gender was found to be associated with academicpurpose computer-using time, while male gender was associated with game-related computer-using time. Early popular stereotypes and research on computer attitudes described the typical people affected by Internet addiction as technologically sophisticated male loners. ${ }^{1}$ More recently, it has been suggested that men and women use the Internet differently, and that males are more likely to meet criteria for Internet addiction than females. ${ }^{39}$ It has been proposed that males, compared to females, may be more prone to problematic Internet use because they are more likely to use the application for games, cybersex, and gambling activities that are associated with compulsive or problematic use. ${ }^{10}$ Conversely, women with Internet addiction tend to seek close friendships online. ${ }^{9}$ Our findings are consistent with gender differences in Internet use and vulnerability to adverse exposure/experiences that need to be taken into account in future research.

Lower academic level was associated with game-related computer overuse. In Taiwan, potential risk factors for Internet addiction in adolescents have been identified to be low participation in school communities, greater substance-use experience, high family conflict, and low family function. ${ }^{40}$ The school milieu and ethos in the current school setting might have contributed to the association between computer overuse and academic achievement. The association between game-related computer overuse and above average height is less easily explained and could represent type 1 statistical er- ror, given the number of exposure-outcome relationships examined. However, it is possible that above average height indicates more rapid growth and more advanced pubertal stages, which may themselves influence computer use and the likelihood of an adolescent challenging their parents' regulation. This finding requires independent replication, although a similar process may account for higher game-related overuse in participants with an older sibling. ${ }^{4}$

Certain limitations should be considered. First, we used time spent on the computer as an index of the level of preoccupation with computer use or Internet use, without taking into account tolerance, withdrawal, or adverse consequences. Studies with case-control design, comparing problematic users with non-problematic users, generally agree that problematic users spend significantly more time on the Internet. ${ }^{9}{ }^{10} \mathrm{We}$ took three hours per day as a definition of problematic computer overuse. We calculated cut-offs for these aspects of use separately, so that some adolescents with combined computer overuse (e.g., academic-purpose for two hours and game-purpose for two hours) might have been missed, although this situation occurred in less than $5 \%$ of the sample. Second, the problematic Internet experiences measured were not necessarily representative of all problematic Internet experiences, and the measures used to assess cyber-bullying victimisation asked about e-mail, chat room, text message, and phone media only (not social networks, for example, which were less of a feature at the time of the study, but have clearly emerged rapidly since that time). Third, the adolescents in this study cannot be assumed to be nationally or internationally representative, and further research is required to investigate the extent to which such associations are specific to particular schools, settings or cultures.

\section{Clinical implications}

This study used longitudinal data with environmental and psychological factors being measured at age 13 years, before online sexual harassment, cyber-bullying victimisation, and computer-using time was measured at age 15 years. Some familial factors are associated with problematic Internet experiences and computer-using time, suggesting that recent approaches aimed at reducing Internet-related problems should focus education on family monitoring and supervising their adolescents. Obviously, professional advice and family Internet policies need to take into account the culture of their society and their family.

\section{Acknowledgments}

This work has been funded by a grant of the Korea Health 21 R\&D, Ministry of Health and Welfare, Republic of Korea (A050047). We are very grateful to all the families who participated in this study and the school personnel who supported the work. 


\section{REFERENCES}

1. Shotton MA. The costs and benefits of "computer addiction". Behav Inform Technol 1991;10:219-230.

2. Young KS. Psychology of computer use: XL. Addictive use of the Internet: a cast that breaks the stereotype. Psychol Rep 1996;79:899-902.

3. Guan SA, Subrahmanyam K. Youth internet use; risks and opportunities. Curr Opin Psychiatry 2009;22:351-356.

4. Mitchell KJ, Finkelhor D, Wolak J. Risk factors for and impact of online sexual solicitation of youth. JAMA 2001;285:3011-3014.

5. Mitchell KJ, Wells M. Problematic internet experiences: primary or secondary presenting problems in persons seeking mental health care? Soc Sci Med 2007;65:1136-1141.

6. Kowalski RM, Limber SP. Electronic bullying among middle school students. J Adolesc Health 2007;41(Suppl 1):S22-S30.

7. Perren S, Dooley J, Shaw T, Cross D. Bullying in school and cyberspace: associations with depressive symptoms in Swiss and Australian adolescents. Child Adolesc Psychiatry Ment Health 2010;4:28.

8. Pornari CD, Wood J. Peer and cyber aggression in secondary school students: the role of moral disengagement, hostile attribution bias, and outcome expectancies. Aggress Behav 2010;36:81-94.

9. Young KS, Rodgers RC. The relationship between depression and Internet addiction. Cyberpsychol Behav 1998;1:25-28.

10. Morahan-Martin J, Schumacher P. Incidence and correlates of pathological Internet use among college students. Comput Human Behav 2000;16:13-29.

11. Kim JW, Han DH, Park DB, Min KJ, Na C, Won SK, et al. The relationships between online game player biogenetic traits, playing time, and the genre of the game being played. Psychiatry Investig 2010;7:17-23.

12. Dooley J, Pyzalski J, Cross D. Cyberbullying versus face-to-face bullying: a theoretical and conceptual review. J Psychology 2009;217:182188.

13. Ha JH, Yoo HJ, Cho IH, Chin B, Shin D, Kim JH. Psychiatric comorbidity assessed in Korean children and adolescent who screen positive for internet addiction. J Clin Psychiatry 2006;67:821-826.

14. Austin S, Joseph S. Assessment of bully/victim problems in 8 to 11 yearolds. Br J Educ Psychol 1996;66:447-456.

15. Lee CJ, Kwak KJ. Self-concept and social support according to bullying types. Korean J Dev Psychol 2000;13:65-80.

16. Kovacs M. The Children's Depression Inventory (CDI). Psychopharmcol Bull 1985;21:995-998.

17. Cho SC, Lee YS. Development of the Korean form of the Kovacs' Children's Depression Inventory. J Korean Neuropsychiatr Assoc 1990;29: 943-956.

18. Spielberger CD, Gorsuch RL, Lushene RE. Manual for the State-Trait Anxiety Inventory for Children. Palo Alto, CA: Consulting Psychologists Press; 1970

19. Cho SC, Choi JS. Development of the Korean form of the State-Trait Anxiety Inventory for Children. Seoul J Psychiatry 1989;14:150-157.

20. Coopersmith S. Self-Esteem Inventories. Palo Alto, CA: Consulting Psychologists Press; 1981.

21. Kim KY. Self-Esteem and Child-Rearing Attitudes to Children's SelfEsteem. Graduate School of Home Management. Busan: Pusan Na- tional University; 1987

22. Halstead M, Johnson SB, Cunningham W. Measuring coping in adolescents: An application of the Ways of Coping Checklist. J Clin Child Psychol 1993;22:337-344.

23. Kang JJ. Relationship between Satisfaction of Body Image and Stress Coping Style. Graduate School of Psychology. Seoul: Ehwa Women's University; 2001.

24. Goodman R, Meltzer H, Bailey V. The Strengths and Difficulties questionnaire: A pilot study on the validity of the self-report version. Eur Child Adolesc Psychiatry 1998;7:125-130.

25. Ahn JS, Jun SK, Han JK, Noh KS, Goodman R. The development of a Korean version of the Strengths and Difficulties Questionnaire. J Korean Neuropsychiatr Assoc 2003;42:141-147.

26. So YK, Noh JS, Kim YS, Ko SG, Koh YJ. The reliability and validity of Korean parent and teacher ADHD rating scale. J Korean Neuropsychiatr Assoc 2002;41:283-289.

27. Schafer JL. Analysis of Incomplete Multivariate Data. London: Chapman and Hall; 1997.

28. Smith PK, Mahdavi J, Carvalho M, Fisher S, Russell S, Tippett N. Cyberbullying: its nature and impact in secondary school pupils. J Child Psychol Psychiatry 2008;49:376-385.

29. Williams KR, Guerra NG. Prevalence and predictors of internet bullying. J Adolesc Health 2007;41(Suppl 1):S14-S21.

30. International KCR. National Survey of Internet Use in Korea. Seoul, Korea: Korean Click Report Korean Click Corps; 2004.

31. Liu T, Potenza MN. Problematic internet use: clinical implications. CNS Spectr 2007;12:453-466.

32. Weinstein A, Lejoyeux M. Internet addiction or excessive internet use. Am J Drug Alcohol Abuse 2010;36:277-283.

33. Gentile DA, Choo H, Liau A, Sim T, Li D, Fung D, et al. Pathological video game use among youths: a two-year longitudinal study. Pediatrics 2011;127:e319-e329.

34. Southern S. Treatment of compulsive cybersex behavior. Psychiatr Clin North Am 2008;31:697-712.

35. Ko CH, Yen JY, Chen CC, Chen SH, Wu K, Yen CF. Tridimensional personality of adolescents with Internet addiction and substance use experience. Can J Psychiatry 2006;51:887-894.

36. Brand M, Laier C, Pawlikowski M, Schachtle U, Scholer T, AltstotterGleich C. Watching pornographic pictures on the Internet; role of sexual arousal ratings and psychological-psychiatric symptoms for using internet sex sites excessively. Cyberpsychol Behav Soc Netw 2011;14:371377.

37. Naylor P, Cowie H, del Rey R. Coping strategies of secondary school children in response to being bullied. Child Psychol Psychiatry Rev 2001;6:114-120.

38. Raskauskas J, Stoltz AD. Involvement in traditional and electronic bullying among adolescents. Dev Psychol 2007;43:564-575.

39. Chou C, Condron L, Belland JC. A review of the research on internet addiction. Educ Psychol Rev 2005; 17:363-388.

40. Yen CF, Ko CH, Yen JY, Chang YP, Cheng CP. Multi-dimensional discriminative factors for Internet addiction among adolescents regarding gender and age. Psychiatry Clin Neurosci 2009;63:357-364. 